\title{
Structural Change and Inequality
}

\section{Camilo Andrés Mesa Salamanca, Hernando Zuleta Gonzalez}

Faculty of Economics, Universidad de Los Andes, Bogotá, Colombia

Email: ca.mesa@uniandes.edu.co,h.zuleta@uniandes.edu.co

How to cite this paper: Mesa, C. A., \& Zuleta, H. (2021). Structural Change and Inequality. Theoretical Economics Letters, 11, 391-403.

https://doi.org/10.4236/tel.2021.113026

Received: April 2, 2021

Accepted: May 7, 2021

Published: May 10, 2021

Copyright $\odot 2021$ by author(s) and Scientific Research Publishing Inc. This work is licensed under the Creative Commons Attribution International License (CC BY 4.0).

http://creativecommons.org/licenses/by/4.0/

\begin{abstract}
We build a theoretical model of demand-driven structural change where individuals have different endowments of productive factors. These differences in endowments generate income inequality. The main result is that for economies with a low factor endowment (poor economies), an increase in inequality can accelerate structural change.
\end{abstract}

\section{Keywords}

Structural Change, Income Distribution, Economic Growth

\section{Introduction}

Does income inequality influence the relative size of economic sectors? We present a simple theoretical model to answer this question. The short answer is yes. Suppose the income elasticity of demand changes with the income level and is different for different goods. In that case, a change in income distribution affects the demand for other goods and the allocation of factors between different sectors.

In general, as economies grow, they experience a change in the relative size of the sectors: the share of the primary sector decreases (activities directly related to natural resources), while the share of the rest of the sectors increases. This process, usually called structural change, is recognized in the economic literature and is documented in different papers ${ }^{1}$.

Structural change is a modern phenomenon associated with economic growth that includes a gradual reallocation of employment from the agricultural to the industrial sector and then to the service sector. This structural transformation, however, follows different dynamics in different countries.

${ }^{1}$ Rostow (1959), Chenery (1960) and Kuznets (1966) provided the first contributions on growth and structural change. See Pasinetti (1983), Chenery et al. (1986), Acemoglu (2008), Herrendorf et al. (2014), Kruger (2008) among others. 
The literature on structural change can be divided into two groups: demanddriven and supply-driven structural change. In demand-driven models, the increase in income allows people to overcome a subsistence consumption of agricultural goods. Once the income is above the subsistence level, individuals spend on manufacturing goods and services. Then, additional increments in income generate a less than proportional increase in the consumption of agricultural goods ${ }^{2}$.

In supply-driven models, the reallocation of factors occurs because of sectoral differences in the productivity of factors or different rates of technological change. Economic growth comes with a change in the relative abundance of factors, sectors where reproducible factors are used more intensely to grow faster than sectors where not reproducible factors are used less intensively ${ }^{3}$.

Alvarez-Cuadrado \& Poschke (2011) studied the two perspectives on structural change for 12 countries during the $19^{\text {th }}$ and $20^{\text {th }}$ centuries and found that the demand effect explains the structural change to the First World War. The supply effect explains Post-World War II structural change. Then, they conclude that in the first stage of a structural change, the demand side effect is relevant because it drives and pulls the process. In the same way, Swiecki (2017) confirms the importance of structural change mechanisms as sector-biased technological progress and non-homothetic preferences using data between the years 1970 and 2005 for 45 countries.

Authors like Kruger (2008), Acemoglu \& Guerrieri (2008), and Herrendorf et al. (2014) referred to the importance of inequality and its effects on structural change but did not model the causal relation ${ }^{4}$. This paper helps to fill this gap in the literature.

In this context, Matsuyama (2002) studied the appearance of new goods and markets from the increase of both incomes of households and productivity of the firm. The main purpose of this paper is to explain product cycles and understand how during the XX century, new goods started to be consumed by high-income households and, progressively, low-income agents consumed these goods.

The productivity of new goods grows with time so, the price decreases more people consume it. An important issue is that this process depends on income distribution: if the society has high levels of inequality, the product cycle is stopped, and from another side, high equality leads to a poverty trap. So the conclusion is that the income distribution needs to be distributed in specific ways (Matsuyama, 2002).

\footnotetext{
${ }^{2}$ Kongsamut et al. (2001), Foellmi \& Zweimuller (2002), and Buera \& Kaboski (2009, 2012), Matsuyama (2002), among others, provide demand-driven models of structural change.

${ }^{3}$ Acemoglu and Guerrieri (2008) and Zuleta \& Young (2013) among others, provide supply-driven models of structural change.

${ }^{4}$ There are several papers about income distribution and economic growth. See Galor \& Zeira (1993) and Galor \& Tsiddon (1997), among others. However, they do not study the relation between income distribution and structural change.
} 
Similarly, Wang (2019), in a dynamic equilibrium model, analytically discusses the industrialization process from rural income distribution. The relation between the two concepts is closed by the effect on the demand that income causes to produce high productivity goods.

Also, structural change and inequality relationship had been explored as a consequence of wage inequality. Pi \& Zhang (2018), and Mihaylova \& Bratoeva-Manoleva (2018), in the case of the Bulgarian economy, show that structural change affects income inequality and vice versa. The wage inequality is driven by the skills of labor and economic activity. Wang, in a dynamic-equilibrium model, analytically discusses the industrialization process from rural income distribution. The relation between the two concepts is closed by the effect on the demand that income causes to produce high productivity goods.

The empirical literature explores the relation of inequality over structural change. In China, Hao et al. (2020) show that reducing income inequality has given a migration of employment from the agricultural sector to others and produces a convergence among the regions. The mechanism, in this case, is because of migration policy changes that China had in 2000-2015.

In our model, structural change is demand-driven. There are two sectors of production. The first sector produces necessary goods (subsistence sector), and the second sector produces goods that are not necessary (non-subsistence sector). There exists a minimum level of consumption for subsistence goods below which no other good is demanded, so individuals need to overcome this level to consume non-subsistence goods. Once the critical level of income has been exceeded, as the income increases, the consumption of non-subsistence goods grows faster than the consumption of subsistence goods. In these circumstances, in a relatively poor economy, an increase in inequality may increase the demand for non-subsistence goods and generate a change in the sectoral composition of GDP as some individuals overcome the critical income level.

The article is organized as follows. In Section 2, we provide some data on structural change and income inequality to motivate the model. In Section 3, we present the theoretical model. Finally, in Section 4, we conclude.

\section{Income Distribution and the Sectoral Composition of GDP}

The relationship between the sectoral composition of GDP and the income level has been extensively documented, and some authors explore the effect of structural change on income distribution ${ }^{5}$. We explore the inverse causal effect. In this section, we show that, for middle-income and developing countries, there is a negative relation between the Gini coefficient and the share of agriculture. For developed economies countries, there is a positive relation between the Gini coefficient and the share of agriculture.

${ }^{5}$ Some articles that explain the relationship theoretically are Boppart (2014), Ciarli et al. (2010) and Laitner (2000). Empirically: Lin (2011), Bai \& Qian (2010), Cai et al. (2010), Cimoli et al. (2010), Dennis \& Iscan (2009). 
Figure 1 and Figure 2 plot the shares of agriculture and services and the Gini coefficient. The data correspond to different countries in 1992, 2002, and 2012 and the source is the World Bank database. In the case of agriculture, there is a negative correlation between inequality and the share of agriculture for low and middle-income countries. For high-income countries, this correlation is positive.

The relation is the opposite for services: low and middle-income countries show a positive correlation between the share of services and inequality. For high-income countries, the correlation between the share of services and the Gini coefficient is negative.

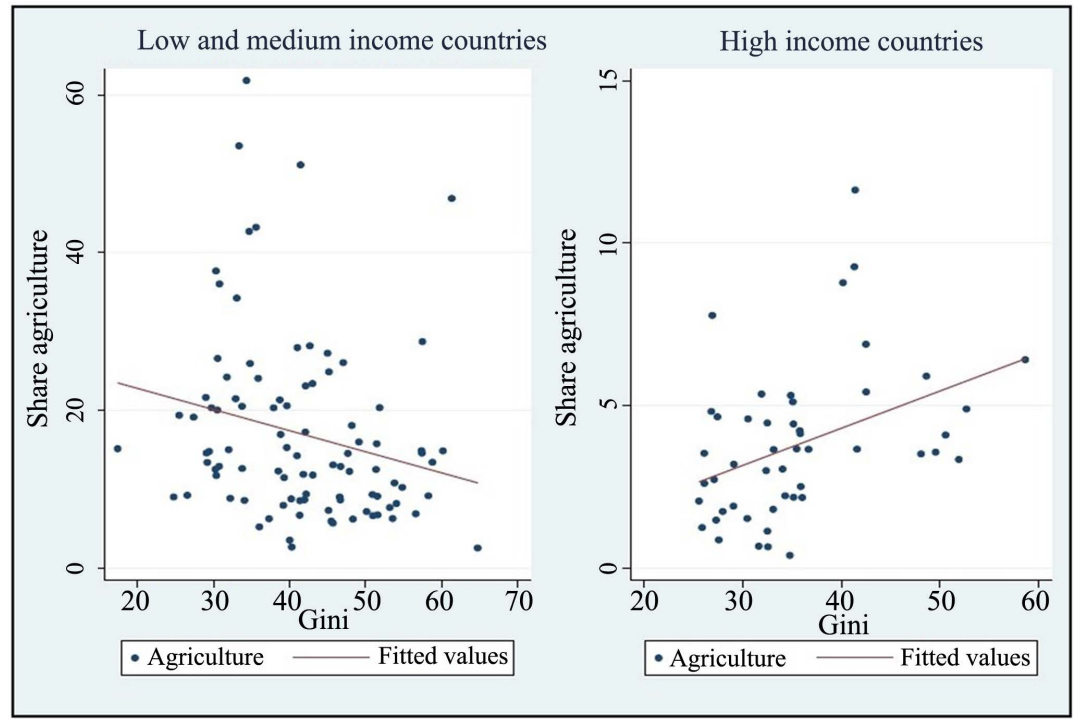

Figure 1. Share of agriculture and the GINI coefficient by groups of countries. (Source: own elaboration with data from the World Bank.)

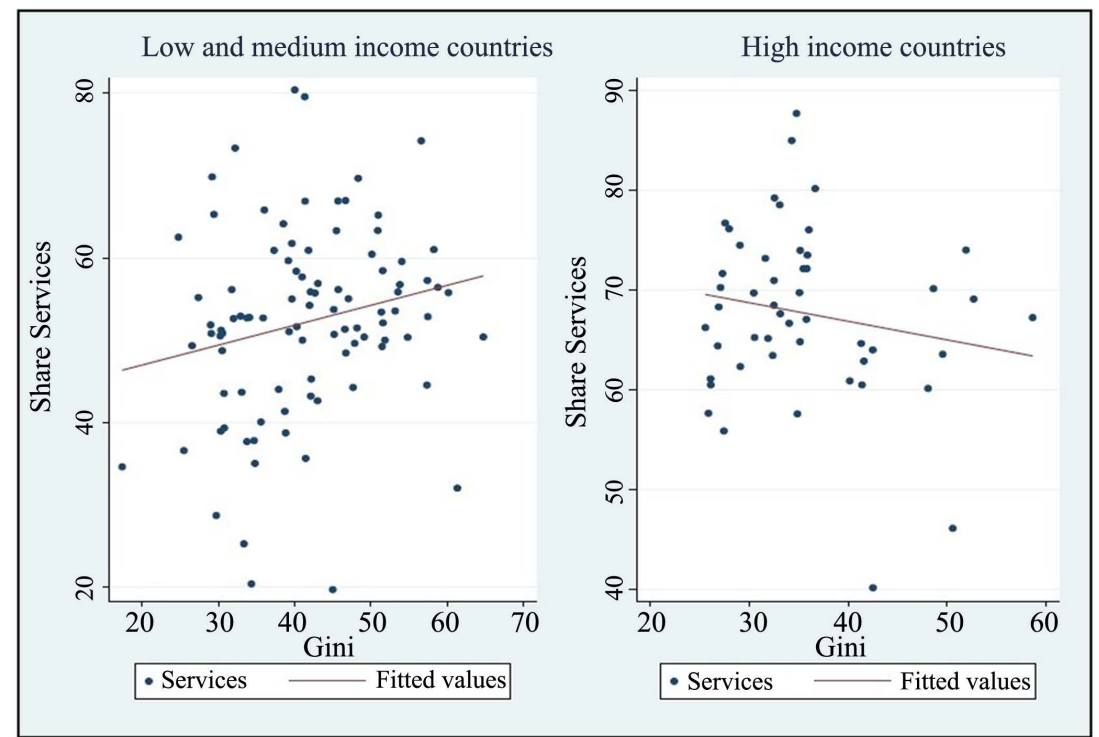

Figure 2. Share of services and the GINI coefficient by groups of countries. (Source: own elaboration with data from the World Bank.) 
Table 1 presents a set of regressions that shows that these correlations are statistically significant. The data correspond to an unbalanced panel of countries in the periods mentioned above. In the first two columns, the dependent variable is the share of agriculture in GDP. For low and middle-income countries, the correlation is negative and significantly different from zero. For high-income countries, the correlation is negative but not significantly different from zero. In the third and fourth columns, the dependent variable is the share of services in GDP; for the case of low and middle-income countries, the correlation is positive and significantly different from zero, and for high-income countries, the correlation is positive but not significantly different from zero.

These results show a relation between the level of inequality and the structural composition of GDP in medium and low-income countries. In other words, Table 1 provides evidence that supports the main prediction of the theoretical model that we present in the next section.

The causality between structural change and income distribution can be twofold. On the one hand, structural change can affect the relative remuneration of factors and, in this way, the distribution of income. On the other hand, the distribution of income affects the demand for goods produced by each sector differently. However, this section aims to motivate the model and not solve the causality issue.

\section{Model of Structural Change and Income Inequality}

The structure of the model follows the traditional analytical framework of sectoral change models but including heterogeneous agents. There are two sectors, $j \in\{a, s\}$, each one produces one good, and there is only one factor of production. Agents own the productive factor and shares of the firms, and they may differ in endowments and, consequently, income levels.

\subsection{Consumers}

Any individual $i$ maximizes a logarithmic utility function:

Table 1. Regressions of sectors share on Gini ${ }^{\mathrm{a}}$.

\begin{tabular}{ccccc}
\hline \multirow{2}{*}{ Table Head } & \multicolumn{4}{c}{ Dependent variable } \\
\cline { 2 - 5 } & $\begin{array}{c}\text { Agriculture } \\
\text { (low and } \\
\text { middle income) }\end{array}$ & $\begin{array}{c}\text { Agriculture } \\
\text { (High income) }\end{array}$ & $\begin{array}{c}\text { Services } \\
\text { (low and } \\
\text { middle income) }\end{array}$ & $\begin{array}{c}\text { Services } \\
\text { (high income) }\end{array}$ \\
\hline GINI & $-0.410^{* *}$ & -0.113 & $0.515^{*}$ & 0.474 \\
Log(gdp per cap) & $(-2.05)$ & $(-0.83)$ & $(1.94)$ & $(0.91)$ \\
Constant & $-16.57^{\star *}$ & -2.000 & $14.35^{* *}$ & 4.158 \\
Observations & $(-6.64)$ & $(-0.68)$ & $(4.32)$ & $(0.37)$ \\
& $163.7^{* *}$ & 27.38 & $-81.07^{* *}$ & 10.51 \\
& $(7.13)$ & $(0.85)$ & $(-2.65)$ & $(0.09)$ \\
\hline
\end{tabular}

a. $t$ statistics in parentheses. ${ }^{\star} p<0.10,{ }^{* *} p<0.05$. Panel data-Fixed effects estimation. Source data: World Bank-World development indicators. 


$$
U= \begin{cases}u_{i}\left(c_{a i}, c_{s i}\right) & \text { if } c_{a i}>\gamma_{a} \\ u_{i}\left(c_{a i}\right) & \text { if } c_{a i} \leq \gamma_{a}\end{cases}
$$

where:

$$
u_{i}\left(c_{a i}, c_{s i}\right)=\log \left(c_{a i}-\gamma_{a}\right)+\log \left(c_{s i}+\gamma_{s}\right)
$$

$c_{a i}$ is the consumption of good $a, \gamma_{a}>0$, is the subsistence level of consumption, $c_{s i}$ is the consumption of good $s$ and the parameter $\gamma_{s}>0$ guarantees that good $s$ is not essential, so, the marginal utility of $C_{s i}$ is finite even if $c_{s i}=0$. In general, utility is an increasing function of consumption. However, when the consumption of good $a$ is equal or lower than the subsistence level, $c_{a i} \leq \gamma_{a}$, the agent only derives utility from the consumption of the essential good $a$. Note also that the marginal utility of consumption is always finite for good $s$ while for good $a$ it goes to infinite when $c_{a i}$ converges to $\gamma_{a}$ from above.

Every individual has an initial endowment of the productive factor $l_{i}>0$ and owns a share $\theta_{i}$ of the firms. The sum of the production factor of the individuals is equal to the total amount of the factor, $\sum_{i=1}^{n} l_{i}=L$ and, the economy is closed, so the domestic agents are the only owners of the firms $\sum_{i=1}^{n} \theta_{i}=1$. For simplicity, we assume that the productive factor and the ownership of the firm are distributed in the same way, $l_{i}=\theta_{i} L$.

We assume factor mobility, so the price of the factor, $w \geq 0$, is the same in the two sectors. We normalize to one the price of good $a$, so $p_{s} \geq 0$ is the relative price of good $s$. Consequently, the budgetary restriction for the individual is:

$$
\theta_{i}\left(w L+\left(\pi_{a}+\pi_{s}\right)\right)=c_{a i}+p_{s} c_{s i}
$$

where $\pi_{a}$ and $\pi_{s}$ are the benefits obtained in sectors $a$ and $s$ respectively.

Therefore, the problem of the consumer is the following:

$$
\max _{c_{a i}, c_{s i}} u_{i}\left(c_{a i}, c_{s i}\right) \text { s.t. } \theta_{i}\left(w L+\left(\pi_{a}+\pi_{s}\right)\right)=c_{a i}+p_{s} c_{s i}
$$

From the first-order conditions, it yields:

$$
\begin{gathered}
c_{a i}=\min \left\{\theta_{i}\left(w L+\left(\pi_{a}+\pi_{s}\right)\right), \frac{\theta_{i}\left[w L+\left(\pi_{a}+\pi_{s}\right)\right]}{2}+\frac{\gamma_{a}}{2}+\frac{\gamma_{s} p_{s}}{2}\right\} \\
c_{s i}=\max \left\{0, \frac{\theta_{i}\left[w L+\left(\pi_{a}+\pi_{s}\right)\right]}{2 p_{s}}-\frac{\gamma_{a}}{2 p_{s}}-\frac{\gamma_{s}}{2}\right\} \\
p_{s}=\max \left(0, \frac{c_{a i}-\gamma_{a}}{c_{s i}+\gamma_{s}}\right)
\end{gathered}
$$

According to Equations (5) and (6), the consumption of the two goods depends on the agents' income. Equation (7) shows the willingness to pay for good $s$, if the consumption of good $a$ is equal or lower than $\gamma_{a},\left(c_{a i} \leq \gamma_{a}\right)$, then agent $i$ is not willing to pay for good $s$.

From Equations (5), (6), and (7), it follows that an individual $i$ does not con- 
sume good $s$ unless her income is above a critical level $\theta_{i}\left[w L+\left(\pi_{a}+\pi_{s}\right)\right]>\left(\gamma_{a}+\gamma_{s} p_{s}\right)$. Now, in the interior solution, when the previous inequality holds, Equations (5) and (6) imply that the income elasticity for $c_{a i}$ is less than one, while the income elasticity for $c_{s i}$ is greater than 1 . This result is relevant because it reflects that when income levels increase, sector $s$ grows faster than a, leading to structural change.

\subsection{Firms}

The production functions are:

$$
Y_{a}=A_{a} L_{a}^{\alpha} \text { and } Y_{s}=A_{s} L_{s}^{\alpha}
$$

where $Y_{a}$ is the production in the sector $a$ and $Y_{s}$ the production in the sector s. $L_{a} \geq 0$ and $L_{s} \geq 0$ are the amounts of factors used in each sector. We also assume perfect mobility of factors and full employment so $L_{a}+L_{s}=L$, where $L$ is the total amount of the factor in the economy.

The parameters $A_{a}$ and $A_{s}$ are constant and represent the productivity. For simplicity, we assume that the parameter $\alpha$, is the same in the two sectors. We also assume, decreasing returns to scale, $\alpha<1$.

Firms maximize profits $\pi_{j}$,

$$
\begin{aligned}
& \max _{L_{a}} \pi_{a}=p_{a} Y_{a}-w L_{a}=A_{a} L_{a}^{\alpha}-w L_{a} \\
& \max _{L_{s}} \pi_{s}=p_{s} Y_{s}-w L_{s}=p_{s} A_{s} L_{s}^{\alpha}-w L_{s}
\end{aligned}
$$

From the first-order conditions, it follows that:

$$
L_{a}=\max \left\{\left(\frac{\alpha A_{a}}{w}\right)^{\frac{1}{1-\alpha}}, L\right\} \text { and } L_{s}=\max \left\{\left(\frac{\alpha A_{s} p_{s}}{w}\right)^{\frac{1}{1-\alpha}}, L\right\}
$$

So, in the interior solution:

$$
\begin{gathered}
\frac{L_{a}}{L_{s}}=\left(\frac{\alpha A_{a}}{\alpha A_{s} p_{s}}\right)^{\frac{1}{1-\alpha}} \\
p_{s}=\frac{A_{a}}{A_{s}}\left(\frac{L_{s}}{L_{a}}\right)^{1-\alpha}
\end{gathered}
$$

We assume full employment, $L_{a}+L_{s}=L$, so Equation (11) implies,

$$
w=\left[\frac{\left(\alpha A_{s} p_{s}\right)^{\frac{1}{1-\alpha}}+\left(\alpha A_{a}\right)^{\frac{1}{1-\alpha}}}{L}\right]^{1-\alpha}
$$

Combining Equations (11) and (14) it yields:

$$
L_{s}=\frac{\left(\alpha A_{s} p_{s}\right)^{\frac{1}{1-\alpha}}}{\left(\alpha A_{s} p_{s}\right)^{\frac{1}{1-\alpha}}+\left(\alpha A_{a}\right)^{\frac{1}{1-\alpha}}} L \text { and } L_{a}=\frac{\left(\alpha A_{a}\right)^{\frac{1}{1-\alpha}}}{\left(\alpha A_{s} p_{s}\right)^{\frac{1}{1-\alpha}}+\left(\alpha A_{a}\right)^{\frac{1}{1-\alpha}}} L
$$

Replacing Equation (15) in Equation (8): 


$$
Y_{a}=\frac{A_{a}\left(\alpha A_{a}\right)^{\frac{\alpha}{1-\alpha}} L^{\alpha}}{\left[\left(\alpha A_{s} p_{s}\right)^{\frac{1}{1-\alpha}}+\left(\alpha A_{a}\right)^{\frac{1}{1-\alpha}}\right]^{\alpha}} \text { and } Y_{s}=\frac{A_{s}\left(\alpha A_{s} p_{s}\right)^{\frac{\alpha}{1-\alpha}} L^{\alpha}}{\left[\left(\alpha A_{s} p_{s}\right)^{\frac{1}{1-\alpha}}+\left(\alpha A_{a}\right)^{\frac{1}{1-\alpha}}\right]^{\alpha}}
$$

Finally:

$$
\frac{Y_{a}}{Y_{s}}=\left(\frac{A_{a}}{A_{s}}\right)^{\frac{1}{1-\alpha}}\left(\frac{1}{p_{s}}\right)^{\frac{\alpha}{1-\alpha}}
$$

From Equations (11) to (17) it follows that, in the corner solution, the relative price of good $s$ is zero, $p_{s}=0$, the factor of production is entirely devoted to sector $a, Y_{a}=A_{a} L^{\alpha}$, and wages and benefits are given by $w=\alpha A_{a} L^{\alpha-1}$ and $\pi_{a}=(1-\alpha) A_{a} L^{\alpha}$.

Proposition 1: Given $A_{a}, A_{s}$, and $L$; in the interior solution, the equilibrium price $p_{s}$ and the allocation of labor is such that. $A_{a} L^{\alpha} \leq A_{a} L_{a}^{\alpha}+p_{s} A_{s} L_{s}^{\alpha}$

Proof:

1) If there is a corner solution, then $p_{s}=0, L_{s}=0, L_{a}=L$ and $A_{a} L^{\alpha}=A_{a} L_{a}^{\alpha}$.

2) If there is an interior solution, then $L \geq L_{a}$ so, $L^{\alpha-1} \leq L_{a}^{\alpha-1}$. Multiplying both sides for $A_{a} L$, yields $A_{a} L^{\alpha} \leq A_{a} L L_{a}^{\alpha-1}$, using $L_{a}+L_{s}=L$, then we have $A_{a} L^{\alpha} \leq A_{a} L_{a}^{\alpha-1}\left(L_{a}+L_{s}\right)$.

3) Rearranging, $A_{a} L^{\alpha} \leq A_{a} L_{a}^{\alpha}+A_{a} L_{a}^{\alpha-1} L_{s}$; multiplying and dividing the last term by $A_{s} L_{s}^{\alpha}, A_{a} L^{\alpha} \leq A_{a} L_{a}^{\alpha}+\frac{A_{a}}{A_{s}}\left(\frac{L_{s}}{L_{a}}\right)^{1-\alpha} A_{s} L_{s}^{\alpha}$.

4) Finally, replacing $p_{s}=\frac{A_{a}}{A_{s}}\left(\frac{L_{s}}{L_{a}}\right)^{1-\alpha}$, yields $A_{a} L^{\alpha} \leq A_{a} L_{a}^{\alpha}+p_{s} A_{s} L_{s}^{\alpha}$.

\subsection{General Equilibrium: Income Inequality and Structural Change}

This section introduces the analysis of income inequality between individuals and studies the way in which structural change is affected when the distribution deteriorates.

For simplicity, we assume that the economy has only two individuals, and depending on their initial endowments, can consume or not good $s$.

\section{Equilibrium.}

An allocation of factors $\left[L_{a}, L_{s}\right]$, a vector of prices $\left[p_{s}, w\right]$ and a vector of consumption $\left[c_{a i}, c_{s i}\right]_{i=1}^{n}$ such that: firms in each productive sector $[a, s]$ maximize their benefits $\left[\pi_{a}, \pi_{s}\right]$ given the total supply of productive factor $L$ and allocations of productive factor $\left[l_{i}\right]_{i=1}^{n}$ (in such a way that satisfies Equations (8) to (17)), and individuals maximize utility subject to the budget restriction and their initial endowment of productive factor $\left[l_{i}\right]_{i=1}^{n}$.

Equilibrium without inequatlity.

Considering a situation in which there is perfect income distribution, from 
Equations (7) and (13) for any agent $i$, it holds:

$$
p_{s}=\max \left(0, \frac{c_{a i}-\gamma_{a}}{c_{s i}+\gamma_{s}}\right)=\frac{A_{a}}{A_{s}}\left(\frac{L_{s}}{L_{a}}\right)^{1-\alpha}
$$

Therefore, if $c_{a i} \leq \gamma_{a}$ the $L_{s}=0$. Equation (18) is the relative price of sector $s$ under equilibrium of households and firms.

Now, given that $c_{a 1}=c_{a 2}$, from Equation (7) it follows that the total consumption of sectors $a$ and $s$ is given by:

$$
\begin{gathered}
C_{a}=\frac{w L+\pi_{a}+\pi_{s}}{2}+\left(\gamma_{a}+\gamma_{s} p_{s}\right) \\
C_{s}=\max \left\{0, \frac{w L+\pi_{a}+\pi_{s}}{2 p_{s}}-\left(\frac{\gamma_{a}}{p_{s}}+\gamma_{s}\right)\right\}
\end{gathered}
$$

Since there is no investment in this economy, total consumption is equal to total output: $C_{a}=Y_{a}$ and $C_{s}=Y_{s}$. Similarly, from Equations (8) to (16) it follows that $w L+\pi_{a}+\pi_{s}=A_{a} L_{a}^{\alpha}+p_{s} A_{s} L_{s}^{\alpha}$. Therefore, we can rewrite Equations (19) and (20):

$$
\begin{gathered}
A_{a} L_{a}^{\alpha}=\frac{A_{a} L_{a}^{\alpha}+p_{s} A_{s} L_{s}^{\alpha}}{2}+\left(\gamma_{a}+\gamma_{s} p_{s}\right) \\
A_{s} L_{s}^{\alpha}=\max \left\{0, \frac{A_{a} L_{a}^{\alpha}+p_{s} A_{s} L_{s}^{\alpha}}{2 p_{s}}-\left(\frac{\gamma_{a}}{p_{s}}+\gamma_{s}\right)\right\}
\end{gathered}
$$

And solve for $L_{a}$ and $L_{s}$ :

$$
\begin{gathered}
L_{a}=\left[\frac{p_{s}}{A_{a}}\left(A_{s} L_{s}^{\alpha}+2 \gamma_{s}\right)+\frac{2}{A_{a}} \gamma_{a}\right]^{\frac{1}{\alpha}} \\
L_{s}=\max \left\{0,\left[\frac{A_{a} L_{a}^{\alpha}}{A_{s} p_{s}}-\frac{2}{A_{s}}\left(\frac{\gamma_{a}}{p_{s}}+\gamma_{s}\right)\right]^{\frac{1}{\alpha}}\right\}
\end{gathered}
$$

Now, since in an economy without inequality $L=l_{1}+l_{2}$ and $l_{1}=l_{2}$, exists a critical level for factors that we define as $\tilde{L}$ and $\tilde{l}$ such that:

$$
\tilde{L}=\left[\frac{2}{A_{a}} \gamma_{a}\right]^{1 / \alpha} \text { and } \tilde{l}=\frac{1}{2}\left[\frac{2}{A_{a}} \gamma_{a}\right]^{1 / \alpha}
$$

Proposition 2: $L>\tilde{L}$ is a necessary and sufficient condition for the interior solution.

Proof:

1) If $L \leq\left[\frac{2}{A_{a}} \gamma_{a}\right]^{\frac{1}{\alpha}}$ then $L_{a} \leq\left[\frac{2}{A_{a}} \gamma_{a}\right]^{\frac{1}{\alpha}}$ and Equation (23) cannot hold unless $p_{s} \leq 0$. However, from Equation (7) it follows that in the interior solution $p_{s}>0$. Therefore, $L>\left[\frac{2}{A_{a}} \gamma_{a}\right]^{\frac{1}{\alpha}}$ is a necessary condition for interior solution. 
2) If $L>\left[\frac{2}{A_{a}} \gamma_{a}\right]^{1 / \alpha}$ then $p_{s}>0$ and $L_{s}>0$ so sector $s$ is active: from Equations (21) and (24) it follows that if $p_{s}>0$ then $L_{s}>0$. If $L>\left[\frac{2}{A_{a}} \gamma_{a}\right]^{1 / \alpha}$ then from Equation (23) and from $L=L_{a}+L_{s}$, it follows if $L_{s}=0$ then $L_{a}>\left[\frac{2}{A_{a}} \gamma_{a}\right]^{1 / \alpha}$. However, if $L_{a}>\left[\frac{2}{A_{a}} \gamma_{a}\right]^{1 / \alpha}$ then $C_{a}>2 \gamma_{a}$ and $c_{a i}>\gamma_{a}$, so $p_{s}>0$ and from Equation (18) $L_{s}$ cannot be 0, so $L_{s}>0$.

3) From the last items, it follows that if $L>\left[\frac{2}{A_{a}} \gamma_{a}\right]^{1 / \alpha}$, then $p_{s}>0$ and $L_{s}>0$. Therefore, $L>\left[\frac{2}{A_{a}} \gamma_{a}\right]^{\frac{1}{\alpha}}$ is a sufficient condition for interior solution.

The expression $L>\tilde{L}$ shows that when the total income or total consumption of the sector $a$ is greater than the level of essential consumption for life $\left(A_{a} L^{\alpha}>2 \gamma_{a}\right)$ sector $s$ is active. In this way, when $L>\tilde{L}$ or $l_{i}>\tilde{l}$ sector $s$ is active, and the economy has structural change.

Equilibrium with inequatlity.

Case 1: $\tilde{L} \geq L>\left[\frac{\gamma_{a}}{A_{a}}\right]^{1 / \alpha}, \theta_{1}>\theta_{2}$.

From case 1 it is clear that if $L \leq\left[\frac{2}{A_{a}} \gamma_{a}\right]^{1 / \alpha}$ and there is no inequality; then there is no production of good $s$. However, if there is inequality, then sector $s$ may be active. In particular, suppose that agent 1 owns more than half of the available factors, and her income is sufficient to consume more than the subsistence level.

Proposition 3: if $\tilde{L} \geq L>\left[\frac{\gamma_{a}}{A_{a}}\right]^{1 / \alpha}$, and $\theta_{1}>\frac{\gamma_{a}}{A_{a} L^{\alpha}}$, then $c_{s 1}>0$.

Proof:

1) From proposition 1 , if $\theta_{1}\left[A_{a} L^{\alpha}\right]>\gamma_{a}$ then $\theta_{1}\left[A_{a} L_{a}^{\alpha}+p_{s} A_{s} L_{s}^{\alpha}\right]>\gamma_{a}$. Therefore, if $\theta_{1}>\frac{\gamma_{a}}{\left[A_{a} L^{\alpha}\right]}$ then $\theta_{1}>\frac{\gamma_{a}}{\left[A_{a} L_{a}^{\alpha}+p_{s} A_{s} L_{s}^{\alpha}\right]}$ and $\theta_{1}>\frac{\gamma_{a}}{\left[w L+\pi_{a}+\pi_{s}\right]}$.

2) In equilibrium $c_{s 1}=\frac{\theta_{1}\left[w L+\pi_{a}+\pi_{s}\right]}{2 p_{s}}-\frac{\gamma_{a}}{2 p_{s}}-\frac{\gamma_{s}}{2}$ so, if $\theta_{1}>\frac{\left(\gamma_{a}+\gamma_{s} p_{s}\right)}{\left[w L+\pi_{a}+\pi_{s}\right]}$ then $c_{s 1}>0$.

3) If $L \leq\left[\frac{\gamma_{a}}{A_{a}}\right]^{1 / \alpha}$, then $L_{a} \leq\left[\frac{\gamma_{a}}{A_{a}}\right]^{1 / \alpha}$, and $\frac{\gamma_{a}}{A_{a} L_{a}^{\alpha}}>1$, so $\theta_{1}<\frac{\gamma_{a}}{A_{a} L_{a}^{\alpha}}$. Therefore, $L>\left[\frac{\gamma_{a}}{A_{a}}\right]^{1 / \alpha}$ is a necessary condition for sector $s$ to be active. 
According to proposition 3, in an egalitarian economy where sector $s$ is not active, a redistribution of wealth (an increase in inequality) may lead to an activation of sector $s^{6}$.

Case 2: $L>\tilde{L}, \theta_{1}>\theta_{2}$.

From case 1 it is clear that if $L>\left[\frac{2}{A_{a}} \gamma_{a}\right]^{1 / \alpha}$ and there is no inequality, then there is a production of good $s$, and both agents consume good $s$. However, if there is inequality, then one agent may not consume good $s$. In particular, suppose that agent 2 owns less than half of the available factors, so her income is insufficient to consume more than the subsistence level.

Proposition 4: If $L>\tilde{L}, \theta_{2}<\frac{\gamma_{s}}{\left[A_{s} L^{\alpha}\right]}$ and $\theta_{2}<\frac{\gamma_{a}}{\left[A_{a} L^{\alpha}\right]}$ then $c_{s 2}=0$.

Proof:

The proof is straightforward. If the income of the individual 2 does not overcome the level of subsistence, he devotes all his resources to consume good a, consequently does not consume good $s$.

According to proposition 4, in a situation of inequality where an agent has low income, he does not consume good $s$. In this case, the inequality reduces the consumption of good $s$ for the poor agent and increases the consumption of good $s$ for the rich agent. Therefore, the total effect in the consumption and production in good $s$ depends on the relative strength of the two effects. In other words, the net effect depends on the utility function.

\section{Conclusion}

We explore the relationship between structural change and income inequality using a theoretical model. We concluded that inequality is relevant within the process of structural change. When there is perfect income distribution, but income is low, individuals only consume the subsistence goods. A redistribution of income that generates inequality leads a group to have higher income, allowing that group to consume the subsistence good and the other sector. Thus, under these conditions, a deterioration in the distribution of income leads to structural change within an economy: in high-income countries, a deterioration in the distribution of income has a negative effect on structural change, although for the countries of low-income under this deterioration it has the opposite effect, which is consistent with the evidence suggested by the data.

\section{Conflicts of Interest}

The authors declare no conflicts of interest regarding the publication of this paper.

${ }^{6}$ Not also, if $L \leq\left[\frac{\gamma_{a}}{A_{a}}\right]^{1 / \alpha}$, then $A_{a} L^{\alpha} \leq \gamma_{a}$ and $A_{a} L_{a}^{\alpha} \leq \gamma_{a}$. Therefore, if $L \leq\left[\frac{\gamma_{a}}{A_{a}}\right]^{1 / \alpha}$, then $c_{a i} \leq \gamma_{a}$ for $i=1,2$. 


\section{References}

Acemoglu, D. (2008). Introduction to Modern Economic Growth. Princeton, NJ: Princeton University Press.

Acemoglu, D., \& Guerrieri, V. (2008). Capital Deepening and Nonbalanced Economic Growth. Journal of Political Economy, 116, 467-498. https://doi.org/10.1086/589523

Alvarez-Cuadrado, F., \& Poschke, M. (2011). Structural Change Out of Agriculture: Labor Push versus Labor Pull. American Economic Journal: Macroeconomics, 3, 127-158. https://doi.org/10.1257/mac.3.3.127

Bai, C.-E., \& Qian, Z. (2010). The Factor Income Distribution in China: 1978-2007. China Economic Review, 21, 650-670. https://doi.org/10.1016/j.chieco.2010.08.004

Boppart, T. (2014). Structural Change and the Kaldor Facts in a Growth Model with Relative Price Effects and Non-Gorman Preferences. Econometrica, 82, 2167-2196.

https://doi.org/10.3982/ECTA11354

Buera, F. J., \& Kaboski, J. P. (2009). Can Traditional Theories of Structural Change Fit the Data? Journal of the European Economic Association, 7, 469-477. https://doi.org/10.1162/JEEA.2009.7.2-3.469

Buera, F. J., \& Kaboski, J. P. (2012). The Rise of the Service Economy. American Economic Review, 102, 2540-2569. https://doi.org/10.1257/aer.102.6.2540

Cai, H., Chen, Y., \& Zhou, L.-A. (2010). Income and Consumption Inequality in Urban China: 1992-2003. Economic Development and Cultural Change, 58, 385-413. https://doi.org/10.1086/650423

Chenery, H. B. (1960). Patterns of Industrial Growth. The American Economic Review, 50, 624-654.

Chenery, H. B., Robinson, S., \& Syrquin, M. (1986). Industrialization and Growth. A Comparative Study. Documents and Reports, 74247.

Ciarli, T., Lorentz, A., Savona, M., \& Valente, M. (2010). The Effect of Consumption and Production Structure on Growth and Distribution. A Micro to Macro Model. Metroeconomica, 61, 180-218. https://doi.org/10.1111/j.1467-999X.2009.04069.x

Cimoli, M., Porcile, G., \& Rovira, S. (2009). Structural Change and the Bop-Constraint: Why Did Latin America Fail to Converge? Cambridge Journal of Economics, 34, 389-411. https://doi.org/10.1093/cje/ben060

Dennis, B., \& Iscan, T. (2009). Engel versus Baumol: Accounting for Structural Change Using Two Centuries of U.S. Data. Explorations in Economic History, 46, 186-202. https://doi.org/10.1016/j.eeh.2008.11.003

Foellmi, R., \& Zweimuller, J. (2002). Structural Change and the Kaldor Facts of Economic Growth. Zurich IEER Working Paper, 111.

Galor, O., \& Tsiddon, D. (1997). Technological Progress, Mobility, and Economic Growth. The American Economic Review, 87, 363-382.

Galor, O., \& Zeira, J. (1993). Income Distribution and Macroeconomics. The Review of Economic Studies, 60, 35-52. https://doi.org/10.2307/2297811

Hao, T., Sun, R., Tombe, T., \& Zhu, X. (2020). The Effect of Migration Policy on Growth, Structural Change, and Regional Inequality in China. Journal of Monetary Economics, 113, 112-134. https://doi.org/10.1016/j.jmoneco.2020.03.003

Herrendorf, B., Rogerson, R., \& Valentinyi, A. (2014). Growth and Structural Transformation. In Handbook of Economic Growth (Volume 2, Chapter 6, pp. 855-941). Amsterdam: Elsevier. https://doi.org/10.1016/B978-0-444-53540-5.00006-9 
Kongsamut, P., Rebelo, S., \& Xie, D. (2001). Beyond Balanced Growth. The Review of Economic Studies, 68, 869-882. https://doi.org/10.1111/1467-937X.00193

Kruger, J. J. (2008). Productivity and Structural Change: A Review of the Literature. Journal of Economic Surveys, 22, 330-363. https://doi.org/10.1111/j.1467-6419.2007.00539.x

Kuznets, S. (1966). Modern Economic Growth: Rate Structure, and Spread. London: Yale University Press.

Laitner, J. (2000). Structural Change and Economic Growth. Review of Economic Studies, 67, 545-561. https://doi.org/10.1111/1467-937X.00143

Lin, J. (2011). New Structural Economics: A Framework for Rethinking Development. World Bank Research Observer, 26, 193-221. https://doi.org/10.1093/wbro/lkr007

Matsuyama, K. (2002). The Rise of Mass Consumption Societies. Journal of Political Economy, 110, 1035-1070. https://doi.org/10.1086/341873

Mihaylova, S., \& Bratoeva-Manoleva, S. (2018). Structural Changes and Wage Inequality in the Bulgarian Economy. Eastern Journal of European Studies, 9, 205-227.

Pasinetti, L. (1983). Structural Change and Economic Growth: A Theoretical Essay on the Dynamics of the Wealth of Nations. Cambridge: Cambridge University Press.

Pi, J., \& Zhang, P. (2018). Structural Change and Wage Inequality. International Review of Economics and Finance, 58, 699-707. https://doi.org/10.1016/j.iref.2018.07.010

Rostow, W. W. (1959). The Stages of Economic Growth. The Economic History Review, 12, 1-16. https://doi.org/10.1111/j.1468-0289.1959.tb01829.x

Swiecki, T. (2017). Determinants of Structural Change. Review of Economic Dynamics, 24, 95-131. https://doi.org/10.1016/j.red.2017.01.007

Wang, Y. (2019). A Model of Industrialization and Rural Income Distribution. China Agricultural Economic Review, 11, 507-535. https://doi.org/10.1108/CAER-02-2019-0030

Zuleta, H., \& Young, A. T. (2013). Labor Shares in a Model of Induced Innovation. Structural Change and Economic Dynamics, 24, 112-122.

https://doi.org/10.1016/j.strueco.2012.07.006 